\title{
The gender gap in mobility: A global cross-sectional study
}

\author{
Samia Djemâa Mechakra-Tahiri ${ }^{1}$, Ellen E Freeman ${ }^{2,3^{*}}$, Slim Haddad ${ }^{1}$, Elodie Samson ${ }^{3}$ \\ and Maria Victoria Zunzunegui ${ }^{1}$
}

\begin{abstract}
Background: Several studies have demonstrated that women have greater mobility disability than men. The goals of this research were: 1) to assess the gender gap in mobility difficulty in 70 countries; 2 ) to determine whether the gender gap is explained by sociodemographic and health factors; 3 ) to determine whether the gender gap differs across 6 regions of the world with different degrees of gender equality according to United Nations data.

Methods: Population-based data were used from the World Health Survey (WHS) conducted in 70 countries throughout the world. 276,647 adults aged 18 years and over were recruited from 6 world regions. Mobility was measured by asking the level of difficulty people had moving around in the last 30 days and then creating a dichotomous measure (no difficulty, difficulty). The human development index and the gender-related development index for each country were obtained from the United Nations Development Program website. Poisson regression with Taylor series linearized variance estimation was used.
\end{abstract}

Results: Women were more likely than men to report mobility difficulty (38\% versus $27 \%, \mathrm{P}<0.0001$ ). The ageadjusted prevalence rate ratio for female gender was 1.35 (95\% Cl 1.31-1.38). The addition of education, marital status, and urban versus rural setting reduced the prevalence rate ratio to 1.30 ( $95 \% \mathrm{Cl} 1.26-1.33)$. The addition of the presence of back pain, arthritis, angina, depressive symptoms, and cognitive difficulties further reduced the prevalence rate ratio to $1.12(95 \% \mathrm{Cl}$ 1.09-1.15). There was statistical interaction on the multiplicative scale between female gender and region $(P<0.01)$. The Eastern Mediterranean region, which had the greatest loss of human development due to gender inequality, showed the largest gender gap in mobility difficulty, while the Western Pacific region, with the smallest loss of human development due to gender inequality, had the smallest gender gap in mobility difficulty.

Conclusions: These are the first world-wide data to examine the gender gap in mobility. Differences in chronic diseases are the main reasons for this gender gap. The gender gap seems to be greater in regions with the largest loss of human development due to gender inequality.

Keywords: Gender, Inequality, Mobility, Human development index, Gender-related development index

\section{Background}

Mobility loss is an important global public health issue because it often represents a pre-clinical stage of disability and because it is associated with severe disability, death, and large healthcare expenditures [1-4]. Many studies have demonstrated that women have greater

\footnotetext{
* Correspondence: ellen.e.freeman@umontreal.ca

2Department of Ophthalmology, Université de Montréal, Montreal, Quebec,

Canada

${ }^{3}$ Centre de Recherche de Hôpital Maisonneuve-Rosemont, Montreal, Quebec, Canada

Full list of author information is available at the end of the article
}

mobility disability than men [5-9]. This gap is thought to be due to a greater incidence of mobility disability in women rather than differences in recovery from disability or mortality [6]. Reasons for the gap in mobility disability are not entirely clear but are at least partly due to a greater risk of certain diseases in women (arthritis, depression) that are important to mobility [10-12]. Life course exposures such as physical activity, smoking, diet, childhood hunger, poverty, and body mass index have also been investigated to explain the gender gap. However, two studies did not find evidence that these factors

\section{Biomed Central}


explained the gender gap in mobility [13] and concluded that additional biological and social factors were needed to explain differences in mobility between men and women [14]. Interestingly, there is evidence from a population-based study in Sweden that the gender gap in mobility disability has diminished over time, perhaps as gender equality has improved. In Sweden, the ageadjusted odds ratios for having difficulty climbing stairs, running 100 meters, and walking 100 meters in women versus men decreased from 1968 to 1991 [15]. For example, the age-adjusted odds ratio for having difficulty walking up stairs in women was 2.1 in 1968 while it dropped to 1.5 in subsequent years. This observation led us to question whether the gender gap is different in world regions with different levels of gender equality. The gender mobility gap may be the result of latent and cumulative differences in exposure to mobility risk factors from birth to old age.

The World Health Survey (WHS) data, in which population-based data were collected from 70 countries throughout the world, provide a unique opportunity to examine the gender gap in mobility disability in regions with different profiles of gender equality. We hypothesized that regions with more gender inequality would have a greater difference in mobility disability between women and men. We have recently documented the gender mobility gap in three West African countries using data from WHS [16]. Here, we analysed WHS data to 1) assess the gender gap in mobility difficulty in 70 countries of the world; 2) to determine whether the gender gap is explained by sociodemographic and health factors; 3) to determine whether the gender gap differs across 6 regions of the world with different degrees of gender equality.

\section{Methods}

\section{Study design and population}

The World Health Survey (WHS) is a large, populationbased, cross-sectional study that was conducted in 2002-2003 by the World Health Organization (WHO) in 70 countries including 30 European, 18 African, 7 North and South American, 4 Eastern Mediterranean, 5 Southeast Asian, and 6 Western Pacific countries. Detailed information about the methods of the World Health Survey is available online [17]. A multi-stage, stratified, random cluster sampling strategy was used to identify the participants to be contacted in each country. All sampling plans were reviewed by WHO before implementation. Sampling strata were created based on 3 factors: region, socioeconomic status, and presence of a healthcare facility. Lists of households were obtained from population registries, voter lists, manual enumeration, or other methods. Households were randomly sampled in the selected areas, and within each household, an adult who was 18 years or older was selected using a Kish table. Non-response was carefully documented. Response rates were very good with an average household response rate of $87 \%$ and an average individual response rate of $97 \%$. Informed consent was obtained from all participants and ethics approval was obtained by local institutional review committees. The research complied with the tenets of the Declaration of Helsinki. Also, the Comité d'éthique de la recherche at Maisonneuve-Rosemont Hospital in Montreal approved our use of these data.

\section{Data collection}

Participants answered a face-to-face interviewer-administered questionnaire that was translated into 68 local languages and back-translated using a standard WHO protocol [18]. Briefly, forward translation was done locally by a bilingual multidisciplinary group. Back-translation was then performed by an independent group and was reviewed at the WHO. Any discrepancies were resolved. Finally, a review of the translated questionnaire was performed by a panel of experts.

Mobility difficulty was measured by asking: "Overall in the last 30 days, how much difficulty did you have with moving around?". Responses were rated on a scale of 1 to 5 as follows: 1: None; 2: Mild; 3: Moderate; 4: Severe; 5: Extreme/Cannot do. A dichotomous variable was then created such that those who reported "mild, moderate, severe, or extreme difficulty/cannot do" were compared to those who reported no difficulty. Questions were asked about age, marital status, and level of formal education. The interviewer observed whether the participant lived in an urban, semi-urban, or rural area.

Participants were asked if they had ever been diagnosed with angina or arthritis and if they had experienced the following in the last 30 days : back pain (yes or no), difficulty remembering or concentrating on things (none, mild, moderate, severe, extreme/cannot do). In addition, participants were asked if they had experienced a period of several days when they felt sad, empty, or depressed over the last 12 months (yes, no).

\section{Country-level data}

Country-level data was added to the WHS dataset. In order to determine the level of gender inequality in a country, data from 2003 were obtained on two variables from the United Nations Human Development website [19]. The human development index (HDI) is a composite of 3 factors: life expectancy, educational attainment, and income. The gender-related development index (GDI) measures the same factors as the HDI but the index is penalized for the size of the gap between men and women. The GDI is not meant to be analyzed by itself but rather as a difference or a ratio with the HDI. 
Table 1 Countries that participated in the WHS

\begin{tabular}{ll}
\hline Region & Countries \\
\hline Africa & Burkina Faso, Chad, Côte d'Ivoire, Congo, Comoros, Ethiopia, Ghana, Kenya, Mali, Mauritania, Malawi, \\
Mauritius, Namibia, Senegal, Swaziland, South Africa, Zambia, Zimbabwe \\
Americas & Brazil, Dominican Republic, Ecuador, Guatemala, Mexico, Paraguay, Uruguay \\
Eastern Mediterranean & Morocco, Pakistan, Tunisia, United Arab Emirates \\
Europe & Austria, Belgium, Bosnia and Herzegovina, Croatia, Czech Republic, Denmark, Estonia, Finland, France, \\
& Georgia, Germany, Greece, Hungary, Ireland, Israel, Italy, Kazakhstan, Latvia, Luxembourg, Netherlands, \\
Norway, Portugal, Russian Federation, Slovakia, Slovenia, Spain, Sweden, Turkey, Ukraine, United Kingdom \\
Weutheast Asia & Bangladesh, India, Sri Lanka, Myanmar, Nepal \\
Western Pacific & Australia, China, Lao People's Democratic Republic, Malaysia, Philippines, Viet Nam \\
\hline
\end{tabular}

Bigger differences indicate greater loss of human development due to gender inequality [20]. Table 1 presents all the countries in the WHS and Figure 1 is a map indicating whether the countries are in the lowest tertile of the HDI-GDI difference, the middle tertile, or the highest tertile.

\section{Statistical analysis}

Demographic and health characteristics were compared between men and women and between those with and without mobility difficulty. Percentages and means were adjusted for the complex survey design. Three countries (Slovenia, Guatamala, Zambia) did not report survey design information and were therefore excluded from all analyses. Differences were tested using Pearson's chisquare tests or Student's t-tests taking the complex survey design into account. A series of Poisson regression models with Taylor series linearized variance estimation were performed to examine 1) whether there was a gender gap in mobility difficulty; 2) what sociodemographic or health variables primarily explained the gender gap; and 3) whether the gender gap differed across the 6 world regions (i.e. whether there was interaction between gender and region). We adjusted for the following variables based on their availability in the dataset and prior research indicating their importance to mobility: age, marital status, education, rural versus urban setting, arthritis, angina, depression, back pain, and cognitive difficulty $[9,11,21]$. Interaction was examined by stratification. It was then statistically assessed on a multiplicative scale by creating interaction terms between gender and each region with Africa arbitrarily being chosen as the reference region given it was the region listed first alphabetically. Regression analyses took into account the complex survey design. All analyses were done using the survey estimation (SVY) commands in STATA/IC software version 11.2 (College Station, Texas, USA).

\section{Results}

Table 2 shows the distribution of characteristics of men and women in the WHS. There were statistically significant differences between men and women for all sociodemographic and health variables. The mean ages for men and women in the WHS were 38 and 40 years old

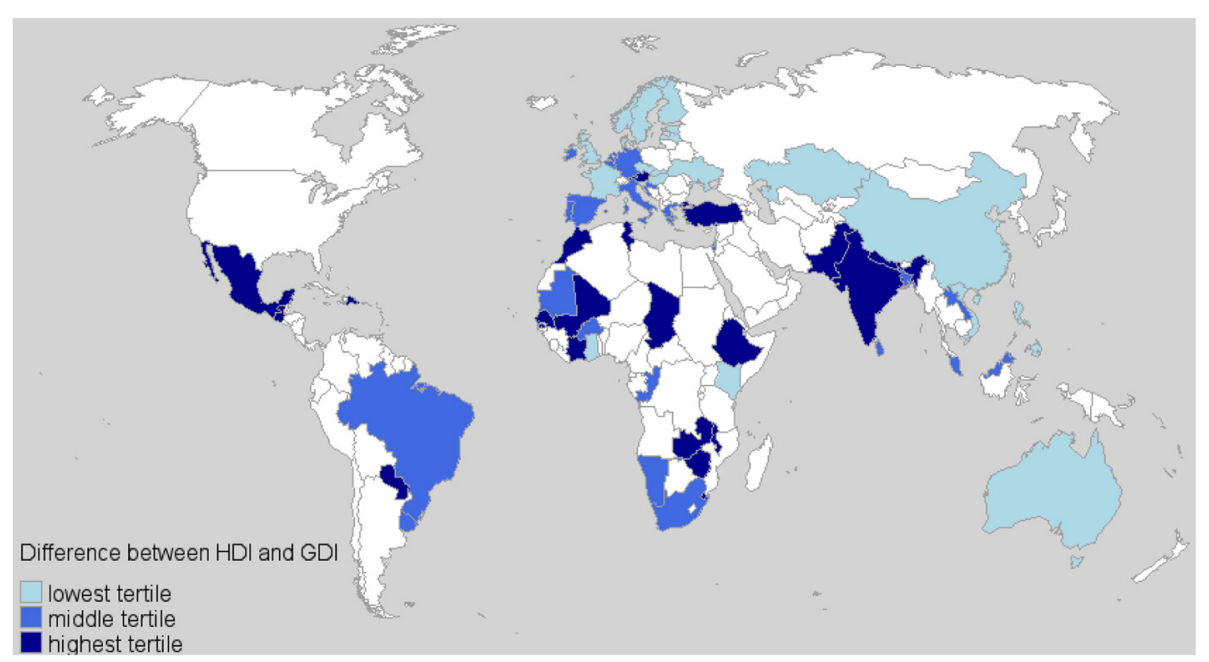

Figure 1 WHS countries by difference between scores on the Human Development and Gender Development Indices. 
Table 2 Characteristics of men and women in WHS ( $n=256,286$ )

\begin{tabular}{|c|c|c|c|}
\hline \multirow[t]{2}{*}{ Characteristic } & \multirow{2}{*}{$\begin{array}{l}\begin{array}{l}\text { Men } \\
(n=126,195)\end{array} \\
\% \text { or Mean }(S D)\end{array}$} & \multirow{2}{*}{$\begin{array}{l}\begin{array}{l}\text { Women } \\
(n=130,091)\end{array} \\
\% \text { or Mean }(S D)\end{array}$} & \multirow[t]{2}{*}{$P$ values } \\
\hline & & & \\
\hline Age, years & $38.4 \pm 16.6$ & $39.7 \pm 16.7$ & 0.029 \\
\hline \multicolumn{4}{|l|}{ Marital Status } \\
\hline Married/cohabiting & 66.2 & 65.4 & $<0.0001$ \\
\hline Never married & 29.1 & 18.0 & \\
\hline Separated/divorced & 2.4 & 5.1 & \\
\hline Widowed & 2.3 & 11.4 & \\
\hline \multicolumn{4}{|l|}{ Education } \\
\hline No school & 18.8 & 30.0 & $<0.0001$ \\
\hline Less than primary & 10.9 & 10.7 & \\
\hline Primary completed & 20.6 & 17.7 & \\
\hline Secondary completed & 21.5 & 18.1 & \\
\hline Greater than secondary & 28.2 & 23.6 & \\
\hline \multicolumn{4}{|l|}{ Setting } \\
\hline Urban & 45.6 & 48.1 & $<0.0001$ \\
\hline Rural & 54.5 & 52.0 & \\
\hline \multicolumn{4}{|l|}{ Back pain } \\
\hline Yes & 28.8 & 40.4 & $<0.0001$ \\
\hline No & 71.2 & 59.6 & \\
\hline \multicolumn{4}{|l|}{ Arthritis } \\
\hline Yes & 10.1 & 15.7 & $<0.0001$ \\
\hline No & 89.9 & 84.3 & \\
\hline \multicolumn{4}{|l|}{ Angina } \\
\hline Yes & 5.7 & 8.0 & $<0.0001$ \\
\hline No & 94.3 & 92.0 & \\
\hline \multicolumn{4}{|l|}{ Depression } \\
\hline Yes & 23.4 & 33.1 & $<0.0001$ \\
\hline No & 76.6 & 66.9 & \\
\hline \multicolumn{4}{|l|}{ Cognitive Difficulties } \\
\hline Any & 30.5 & 42.7 & $<0.0001$ \\
\hline None & 69.5 & 57.3 & \\
\hline
\end{tabular}

respectively. Men were more likely to never have married than women while women were more likely to be widowed $(\mathrm{P}<0.01)$. Women were more likely to not have any formal education and to report all chronic conditions $(\mathrm{P}<0.01)$.

In Table 3, we examined the characteristics of those with and without mobility difficulty. Women were more likely than men to report mobility difficulty (38\% versus $27 \%, \mathrm{P}<0.01)$. Those who were older, had less formal education, lived in rural areas, and had chronic health conditions were more likely to report mobility difficulty $(\mathrm{P}<0.01)$. Marital status was also associated with
Table 3 Characteristics of the study population with and without mobility difficulty

\begin{tabular}{|c|c|c|c|}
\hline & $\begin{array}{l}\text { Mobility } \\
\text { Difficulty }\end{array}$ & $\begin{array}{l}\text { No Mobility } \\
\text { Difficulty }\end{array}$ & $P$ values \\
\hline & $\%$ or Mean $\pm S D$ & $\%$ or Mean $\pm S D$ & \\
\hline Gender & 27.1 & 72.9 & $<0.0001$ \\
\hline Men & 37.9 & 62.1 & \\
\hline
\end{tabular}

Women

Age

Marital Status

$\begin{array}{ccc}46.2 \pm 18.3 & 35.6 \pm 14.7 & <0.0001 \\ 18.6 & 81.4 & <0.0001 \\ 34.3 & 65.7 & \end{array}$

Never married

Married/cohabiting

Separated/divorced

Widowed

\begin{tabular}{|c|c|c|c|}
\hline & 32.1 & 67.9 & \\
\hline & 63.1 & 37.0 & \\
\hline Education & 45.0 & 55.0 & $<0.0001$ \\
\hline No school & 39.0 & 61.0 & \\
\hline Less than primary & 32.4 & 67.6 & \\
\hline Primary completed & 27.0 & 73.0 & \\
\hline Secondary completed & 22.2 & 77.8 & \\
\hline \multicolumn{4}{|l|}{ Greater than secondary } \\
\hline Setting & 28.5 & 71.5 & $<0.0001$ \\
\hline Urban & 36.4 & 63.6 & \\
\hline \multicolumn{4}{|l|}{ Rural } \\
\hline Back pain & 49.5 & 50.5 & $<0.0001$ \\
\hline Yes & 23.8 & 76.2 & \\
\hline \multicolumn{4}{|l|}{ No } \\
\hline Arthritis & 61.2 & 38.8 & $<0.0001$ \\
\hline Yes & 28.1 & 71.9 & \\
\hline \multicolumn{4}{|l|}{ No } \\
\hline Angina & 62.5 & 37.5 & $<0.0001$ \\
\hline Yes & 30.0 & 70.0 & \\
\hline \multicolumn{4}{|l|}{ No } \\
\hline Depression & 46.7 & 53.3 & $<0.0001$ \\
\hline Yes & 26.6 & 73.4 & \\
\hline \multicolumn{4}{|l|}{ No } \\
\hline Cognitive difficulties & 56.9 & 43.1 & $<0.0001$ \\
\hline Any & 18.5 & 81.5 & \\
\hline None & & & \\
\hline
\end{tabular}

mobility difficulty such that those who never married had the least mobility difficulty $(\mathrm{P}<0.01)$.

In Table 4, the prevalence rate ratios for female gender are given adjusting for different sets of covariates while holding the number of observations constant. The ageadjusted prevalence rate ratio for gender in Model 1 was 1.35 (95\% CI 1.31-1.38). In other words, women had a $35 \%$ higher prevalence of mobility difficulty than men. 
Table 4 Poisson regression models showing the changes in the gender gap in mobility difficulty after adjustment

\begin{tabular}{|c|c|c|c|}
\hline & $\begin{array}{l}\text { Model } 1(n=212,744) \\
\text { Mobility Difficulty } \\
\text { PRR }(95 \% \text { Cl) }\end{array}$ & $\begin{array}{l}\text { Model } 2(n=212,744) \\
\text { Mobility Difficulty } \\
\text { PRR (95\% CI) }\end{array}$ & $\begin{array}{l}\text { Model } 3(n=212,744) \\
\text { Mobility Difficulty } \\
\text { PRR }(95 \% \mathrm{Cl})\end{array}$ \\
\hline \multicolumn{4}{|l|}{ Gender } \\
\hline Men & 1.00 & 1.00 & 1.00 \\
\hline Women & $1.35(1.31-1.38)$ & $1.30(1.26-1.33)$ & $1.12(1.09-1.15)$ \\
\hline Age & $1.02(1.02-1.02)$ & $1.02(1.02-1.02)$ & $1.01(1.01-1.01)$ \\
\hline \multicolumn{4}{|l|}{ Marital Status } \\
\hline Married or cohabiting & & 1.00 & 1.00 \\
\hline Never married & & $0.86(0.82-0.91)$ & $0.87(0.83-0.92)$ \\
\hline Separated/Divorced & & $0.93(0.87-0.99)$ & $0.88(0.78-1.02)$ \\
\hline Widowed & & $1.04(1.00-1.08)$ & $0.99(0.96-1.02)$ \\
\hline \multicolumn{4}{|l|}{ Education } \\
\hline Greater than secondary & & 1.00 & 1.00 \\
\hline Secondary completed & & $1.17(1.11-1.23)$ & $1.15(1.10-1.20)$ \\
\hline Primary completed & & $1.29(1.22-1.36)$ & $1.19(1.14-1.25)$ \\
\hline Less than primary & & $1.40(1.32-1.47)$ & $1.22(1.16-1.28)$ \\
\hline No school & & $1.48(1.41-1.56)$ & $1.28(1.22-1.34)$ \\
\hline \multicolumn{4}{|l|}{ Setting } \\
\hline Rural vs. Urban & & $1.20(1.16-1.25)$ & $1.21(1.17-1.26)$ \\
\hline \multicolumn{4}{|l|}{ Back pain } \\
\hline Yes vs. No & & & $1.35(1.31-1.39)$ \\
\hline \multicolumn{4}{|l|}{ Arthritis } \\
\hline Yes vs. No & & & $1.25(1.22-1.28)$ \\
\hline \multicolumn{4}{|l|}{ Angina } \\
\hline Yes vs No & & & $1.19(1.15-1.22)$ \\
\hline \multicolumn{4}{|l|}{ Depression } \\
\hline Yes vs. No & & & $1.19(1.16,1.22)$ \\
\hline \multicolumn{4}{|l|}{ Cognitive Difficulties } \\
\hline Any vs. None & & & $2.23(2.16-2.30)$ \\
\hline
\end{tabular}

$\mathrm{PRR}=$ prevalence rate ratio.

The addition of education, marital status, and urban versus rural setting in Model 2 slightly reduced the prevalence rate ratio for female gender to 1.30 (95\% CI 1.261.33). Adding the 5 health variables (back pain, arthritis, angina, depressive symptoms, and cognitive difficulties) in Model 3 further reduced the prevalence rate ratio for female gender to 1.12 (95\% CI 1.09-1.15).

We then examined whether the gender gap in mobility difficulty differed across world regions by examining region-specific regression models (Table 5). After age adjustment, the gender gap was the largest in the Eastern Mediterranean (prevalence rate ratio $(P R R)=1.66,95 \%$ CI 1.51-1.81) and was the smallest in the Western Pacific (PRR $=1.12$, 95\% CI 1.06-1.18). In the fully adjusted model (Model 3), that pattern remained with the gender gap in the Western Pacific completely disappearing (PRR $=1.03$, 95\% CI 0.98-1.08). Adding interaction terms for gender and world region to an age-adjusted model for all regions combined resulted in statistically significant interactions for the Western Pacific and the Eastern Mediterranean regions compared to Africa (data not shown in Table $5, \mathrm{P}<0.001$ and $\mathrm{P}<0.001$ respectively). In other words, the prevalence rate ratio for female gender in the Eastern Mediterranean was significantly larger than in Africa while the prevalence rate ratio in the Western Pacific was significantly smaller than in Africa. Consistent with this result, of the 6 world regions in the WHS, countries in the Western Pacific region had the smallest difference between the HDI and the GDI while countries in the Eastern Mediterranean region had the largest.

The countries listed as part of the Eastern Mediterranean region by the WHS included Morocco, Pakistan, Tunisia, and the United Arab Emirates (UAE). These 
Table 5 Poisson regression models showing the changes in the gender gap in mobility difficulty by world region

\begin{tabular}{|c|c|c|c|c|}
\hline World Region & $\begin{array}{l}\% \text { with } \\
\text { Mobility Difficulty in } \\
\text { Men and Women }\end{array}$ & $\begin{array}{l}\text { Model } 1 \dagger \\
\text { Mobility Difficulty } \\
\text { PRR }^{*}(95 \% \mathrm{Cl})\end{array}$ & 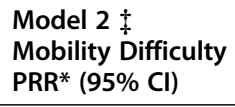 & $\begin{array}{l}\text { Model } 3 \S \\
\text { Mobility Difficulty } \\
\text { PRR* }(95 \% \text { Cl) }\end{array}$ \\
\hline Africa, $n=60,277$ & $23 \%, 31 \%$ & $1.30(1.23-1.37)$ & $1.26(1.20-1.34)$ & $1.11(1.06-1.17)$ \\
\hline Americas, $n=49,803$ & $17 \%, 25 \%$ & $1.37(1.26-1.49)$ & $1.38(1.26-1.50)$ & $1.16(1.06-1.26)$ \\
\hline Eastern Mediterranean $n=16,450$ & $24 \%, 40 \%$ & $1.66(1.51-1.81) \|$ & $1.49(1.36-1.62)$ & $1.17(1.07-1.27)$ \\
\hline Europe $n=40,477$ & $25 \%, 38 \%$ & $1.34(1.24-1.44)$ & $1.32(1.23-1.42)$ & $1.11(1.04-1.19)$ \\
\hline South-east Asia, $n=34,743$ & $35 \%, 49 \%$ & $1.39(1.33-1.45)$ & $1.30(1.24-1.36)$ & $1.16(1.12-1.21)$ \\
\hline Western Pacific, $n=27,236$ & $31 \%, 36 \%$ & $1.12(1.06-1.18) \|$ & $1.09(1.03-1.15)$ & $1.03(0.98-1.08)$ \\
\hline
\end{tabular}

* Prevalence rate ratio for women versus men.

† Model 1: Adjusted by age.

† Model 2: Adjusted by age, marital status, education, and setting.

$\S$ Model 3: Adjusted by age, marital status, education, setting, back pain, arthritis, angina, depression, and cognitive difficulties.

I| In a single regression model for all regions combined (not shown here), interaction terms were statistically significant for the Eastern Mediterranean and the

Western Pacific regions using Africa as the reference region $(P<0.01)$.

countries differ substantially in economic development, religious freedom, and geography. They share in common large Muslim populations. Despite the diversity of these 4 countries, there was not substantial heterogeneity in the age-adjusted prevalence rate ratios for female gender in each of these 4 countries as the prevalence rate ratios ranged from 1.54 (95\% CI 1.12, 2.13) in the United Arab Emirates to 1.96 (95\% CI 1.72, 2.23) in Tunisia. Furthermore, the differences between the human development index and the gender development index for 4 of the 5 countries were in the largest quartile of all the WHS countries (The UAE did not have data on the gender development index). At the other end of the gender equality spectrum, the countries listed as part of the Western Pacific by the WHS included Australia, China, Malaysia, Philippines, Lao People's Democratic Republic, and Vietnam. Again, despite the diversity of these countries, the age-adjusted prevalence rate ratios for female gender were fairly similar ranging from 1.04 (95\% CI $0.99,1.10)$ in the Philippines to 1.39 (95\% CI 1.15, 1.68) in China. The differences between the human development index and the gender development index for 4 of the 6 countries were in the smallest quartile of all the WHS counties while Malaysia and Lao were in the smallest $30^{\text {th }}$ percentile.

\section{Discussion}

This is the first study to use world-wide data to examine the gender gap in mobility disability. The WHS included data from 70 high, middle, and low income countries providing a unique opportunity to compare the gender gap in these diverse socioeconomic and cultural environments. We found support for our hypothesis that regions with more gender inequality would have a greater difference in mobility difficulty between women and men. The region with the largest gender gap in mobility difficulty was the Eastern Mediterranean, which also had the greatest difference between HDI and GDI indicating greater loss of human development due to gender inequality. Conversely, the region with the smallest gender gap in mobility difficulty was the Western Pacific, which had the smallest difference between the HDI and GDI among the 6 world regions of the WHS.

The risk of mobility disability can be reduced by minimizing the risk of chronic conditions by following preventive health practices like getting enough physical activity, treating hypertension and high cholesterol, eating a healthy diet, maintaining a healthy body weight, and not smoking [22]. Clearly, the ability to follow these preventive health practices is impaired without sufficient autonomy and resources, a reality for many men and even more women in the world today. The opportunity to live a healthy lifestyle is essential and it may be deprived of women living in areas with great gender inequality.

Most prior research on the gender gap in mobility disability has been done in the United States $[5,6,8,9]$. A few studies have been done in middle or low income countries. For example, data from a survey of older adults living in 6 Latin American and Caribbean cities found that women were more likely than men to have lower extremity limitations $(\mathrm{OR}=2.29,95 \%$ CI 2.04, 2.79) [23]. A study of 604 older adults in rural Guatemala found that women were more likely than men to report gross mobility disability after age adjustment $(\mathrm{OR}=2.10, \mathrm{P}<0.001)[21]$. Women had greater disability in activities of daily living than men in an older, urban Brazilian population $(\mathrm{OR}=2.16,95 \% \mathrm{CI} 1.32,3.55)$ that persisted even after adjustment for social and health conditions [24]. Two additional studies in the Eastern Mediterranean region have previously reported the gender mobility gap $[25,26]$. Our results greatly add to this prior research by examining this issue on a world-wide basis and including all adults over 18 years of age rather than just older adults.

We found that the gender gap was attenuated after adjusting for health factors. Previous studies done in 
older adults have also reported this, emphasizing arthritis and obesity as two major reasons for the gender gap [9]. Another reason that could explain the gender gap in mobility disability includes an increased risk of sarcopenia in older women [27]. In our data, which included adults of all ages, the two health conditions that caused the biggest decreases in the prevalence rate ratio for gender were back pain and cognitive difficulties. Sociodemographic factors besides gender that were associated with mobility difficulty included older age, being widowed, having no formal education, and living in a rural setting $(\mathrm{P}<0.05)$. A report of a diagnosis of arthritis, a diagnosis of angina, and report of difficulty with cognitive tasks like remembering things or concentrating were also associated with mobility difficulty $(\mathrm{P}<0.05)$.

The major strength of this study is that it includes population-based data from 70 countries from diverse economic and cultural backgrounds. We added to this dataset by including country-level data on gender inequality from the United Nations database. The large sample size in the WHS allowed us to test whether the gender gap in mobility difficulty differed by region, which had never been done before. A limitation of this dataset is that the data are collected by self-report. However, the question on mobility difficulty used by the WHS correlates well with the Timed Up and Go test, an objective measure of mobility [28]. In a sample of 161 older adults at Hôpital Maisonneuve-Rosemont, we found a moderate correlation between the WHS question on mobility difficulty and the Timed Up and Go time in which people are asked to rise from a seated position, walk 3 meters across the room, and return to the chair $(\mathrm{r}=0.51, \mathrm{P}<0.01)$. In addition, as proof of construct validity, we have shown that answers to this question correlate strongly with mobility risk factors in this paper and in our previous publication in 3 African countries [16]. Another limitation is that the cross-sectional nature of this dataset does not allow us to examine the onset or duration of mobility difficulty.

\section{Conclusions}

Women reported greater mobility difficulty than men and this difference was attenuated after adjustment for chronic health conditions. Furthermore, our data suggest that the gender gap in mobility difficulty is greatest in regions that are losing the most human development due to gender inequality. More attention must be devoted to empowering and encouraging men and women across the world to follow preventive health practices like getting enough physical activity, treating hypertension and high cholesterol, eating a healthy diet, maintaining a healthy body weight, and not smoking [22].

\section{Competing interests}

The author(s) declare that they have no competing interests.

\section{Authors' contributions}

ST added the country-level data to the dataset, did analyses, and helped to write the manuscript; EEF did analyses, supervised the project, and helped to write the manuscript; $\mathrm{SH}$ provided expertise on the analysis and manuscript; ES cleaned the WHS data, constructed the world-wide WHS dataset, and reviewed the manuscript; MVZ provided expertise on the analysis and manuscript and provided funding for the project. All authors read and approved the final manuscript.

\section{Acknowledgements}

Funding for this work came from a New Emerging Team grant from the Canadian Institutes of Health Research. Dr. Freeman has a salary award from the Fonds de Recherche en Santé du Québec.

\section{Author details}

${ }^{1}$ Centre de Research de Université de Montréal, Montreal, Quebec, Canada. ${ }^{2}$ Department of Ophthalmology, Université de Montréal, Montreal, Quebec, Canada. ${ }^{3}$ Centre de Recherche de Hôpital Maisonneuve-Rosemont, Montreal, Quebec, Canada.

Received: 26 March 2012 Accepted: 24 July 2012

Published: 2 August 2012

\section{References}

1. Guralnik JM, Ferrucci L, Simonsick EM, Salive ME, Wallace RB: Lowerextremity function in persons over the age of 70 years as a predictor of subsequent disability. N Engl J Med 1995, 332(9):556-561.

2. Ostir GV, Markides KS, Black SA, Goodwin JS: Lower body functioning as a predictor of subsequent disability among older Mexican Americans. J Gerontol A Biol Sci Med Sci 1998, 53(6):M491-M495.

3. Peek MK, Ottenbacher KJ, Markides KS, Ostir GV: Examining the disablement process among older Mexican American adults. Soc Sci Med 2003, 57(3):413-425.

4. Lubitz J, Cai L, Kramarow E, Lentzner H: Health, life expectancy, and health care spending among the elderly. N Engl J Med 2003, 349(11):1048-1055.

5. Newman AB, Brach JS: Gender gap in longevity and disability in older persons. Epidemiol Rev 2001, 23(2):343-350.

6. Leveille SG, Penninx BW, Melzer D, Izmirlian G, Guralnik JM: Sex differences in the prevalence of mobility disability in old age: the dynamics of incidence, recovery, and mortality. J Gerontol B Psychol Sci Soc Sci 2000, 55(1):S41-S50.

7. Leveille SG, Resnick HE, Balfour J: Gender differences in disability: evidence and underlying reasons. Aging (Milano) 2000, 12(2):106-112.

8. Merrill SS, Seeman TE, Kasl SV, Berkman LF: Gender differences in the comparison of self-reported disability and performance measures. J Gerontol A Biol Sci Med Sci 1997, 52(1):M19-M26.

9. Whitson HE, Landerman LR, Newman AB, Fried LP, Pieper CF, Cohen HJ: Chronic medical conditions and the sex-based disparity in disability: the Cardiovascular Health Study. J Gerontol A Biol Sci Med Sci 2010, 65(12):1325-1331.

10. Petrea RE, Beiser AS, Seshadri S, Kelly-Hayes M, Kase CS, Wolf PA: Gender differences in stroke incidence and poststroke disability in the Framingham heart study. Stroke 2009, 40(4):1032-1037.

11. Murtagh KN, Hubert HB: Gender differences in physical disability among an elderly cohort. Am J Public Health 2004, 94(8):1406-1411.

12. Yount KM, Hoddinott J, Stein AD: Disability and self-rated health among older women and men in rural Guatemala: the role of obesity and chronic conditions. Soc Sci Med 2010, 71(8):1418-1427.

13. Zunzunegui MV, Alvarado BE, Beland F, Vissandjee B: Explaining health differences between men and women in later life: a cross-city comparison in Latin America and the Caribbean. Soc Sci Med 2009, 68(2):235-242

14. Kaneda T, Zimmer Z, Fang X, Tang Z: Gender Differences in Functional Health and Mortality Among the Chinese Elderly: Testing an Exposure Versus Vulnerability Hypothesis. Res Aging 2009, 31(3):361-388.

15. Ahacic K, Parker MG, Thorslund M: Mobility limitations in the Swedish population from 1968 to 1992: age, gender and social class differences. Aging (Milano) 2000, 12(3):190-198. 
16. Miszkurka M, Zunzunegui MV, Langlois EV, Freeman EE, Kouanda S, Haddad S: Gender differences in mobility disability during young, middle and older age in West African adults. Public Health: Glob; 2011.

17. Tay T, Rochtchina E, Mitchell P, Lindley R, Wang JJ: Eye care service utilization in older people seeking aged care. Clin Experiment Ophthalmol 2006, 34(2):141-145.

18. Moussavi S, Chatterji S, Verdes E, Tandon A, Patel V, Ustun B: Depression, chronic diseases, and decrements in health: results from the World Health Surveys. Lancet 2007, 370(9590):851-858.

19. Palagyi A, Ramke J, du Toit R, Brian G: Eye care in Timor-Leste: a population-based study of utilization and barriers. Clin Experiment Ophthalmol 2008, 36(1):47-53.

20. Schuler D: The uses and misuses of the gender-related development index and the gender empowerment measure: A review of the literature. Journal of Human Development and Capabilities 2007, 7(2):161-181.

21. Yount KM, Hoddinott J, Stein AD: Disability and self-rated health among older women and men in rural Guatemala: the role of obesity and chronic conditions. Soc Sci Med 2010, 71(8):1418-1427.

22. United, Nations: Prevention and control of non-communicable diseases: Report of the Secretary-General; 2011.

23. Alvarado $B E$, Guerra RO, Zunzunegui MV: Gender differences in lower extremity function in Latin American elders: seeking explanations from a life-course perspective. J Aging Health 2007, 19(6):1004-1024.

24. Guerra RO, Alvarado BE, Zunzunegui MV: Life course, gender and ethnic inequalities in functional disability in a Brazilian urban elderly population. Aging Clin Exp Res 2008, 20(1):53-61.

25. Yount KM, Agree EM: Differences in disability among older women and men in Egypt and Tunisia. Demography 2005, 42(1):169-187.

26. Zeki Al Hazzouri A, Mehio Sibai A, Chaaya M, Mahfoud Z, Yount KM: Gender differences in physical disability among older adults in underprivileged communities in Lebanon. J Aging Health 2011, 23(2):367-382.

27. Janssen I, Heymsfield SB, Ross R: Low relative skeletal muscle mass (sarcopenia) in older persons is associated with functional impairment and physical disability. J Am Geriatr Soc 2002, 50(5):889-896.

28. Podsiadlo D, Richardson S: The timed "Up \& Go": a test of basic functional mobility for frail elderly persons. J Am Geriatr Soc 1991, 39(2):142-148.

doi:10.1186/1471-2458-12-598

Cite this article as: Mechakra-Tahiri et al:: The gender gap in mobility: A global cross-sectional study. BMC Public Health 2012 12:598.

\section{Submit your next manuscript to BioMed Central and take full advantage of:}

- Convenient online submission

- Thorough peer review

- No space constraints or color figure charges

- Immediate publication on acceptance

- Inclusion in PubMed, CAS, Scopus and Google Scholar

- Research which is freely available for redistribution 